\title{
ANALISIS DAN DESAIN APLIKASI PENGELOLAAN KERJA PRAKTEK
}

\author{
Ahmad Fauzi Teknik Informatika \\ Universitas Buana Perjuangan Karawang e-mail : afauzi@ubpkarawang.ac.id
}

\begin{abstract}
ABSTRAK
Kerja Praktek merupakan salah satu matakuliah wajib pada program studi berupa kegiatan penempatan praktek kerja mahasiswa perlu dikelola dengan melibatkan pihak-pihak terkait sesuai dengan kebutuhannya. Analisis dan desain aplikasi KP didasarkan pada pemahaman tentang tujuan, struktur, dan proses organisasi serta pengetahuan tentang bagaimana memanfaatkan teknologi informasi untuk keuntungan organisasi. Tujuan penelitian ini adalah menganalisis dan mendesain aplikasi pengelolaan KP sesuai kebutuhan pengelola dan pengguna. Metode pengembangan aplikasi yang dilakukan meliputi tahapan : perencanaan dan seleksi, analisis, desain, serta implementasi dan operasi. Aplikasi dirancang dengan permodelan UML dan diimplementasikan berbasis web. Pengujian oleh pengguna aplikasi sudah sesuai dengan hak aksesnya dan menghasilkan alur pelaksanaan aplikasi yang sesuai kebutuhan dan aturan antarmuka pemakai.
\end{abstract}

Kata Kunci : Kerja Praktek, Analisis, Desain.

\section{PENDAHULUAN}

Kerja Praktek (KP) adalah salah satu matakuliah wajib pada program studi berupa kegiatan penempatan praktek kerja mahasiswa untuk memberi wawasan mengenai penerapan pengetahuan pada dunia usaha/kerja. Mahasiswa mempraktekkan kemampuan dan pengetahuannya dalam menganalisis permasalahan terkait bidang ilmu program studi yang terjadi di dunia kerja/usaha. Mahasiswa dituntut untuk mengembangkan diri, mengembangkan inovasi keilmuan berbasis teknologi dan berkontribusi dalam membantu pemecahan masalah di perusahaan/instansi.

Informasi telah menjadi kebutuhan bagi para penentu keputusan. Internet dan teknologi komunikasi telah membantu kebutuhan informasi tanpa batasan waktu. Aplikasi berbasis web telah tumbuh subur dari perkembangan aplikasi berbasis desktop. Aplikasi berbasis web memberikan kemudahan pengelola maupun pengguna dalam bidang- bidang pekerjaan untuk dapat lebih cepat dan praktis.

Pengelolaan KP perlu dilakukan dengan melibatkan pihak-pihak terkait sesuai dengan kebutuhannya. Sedangkan tahapan kegiatan KP diharapkan dapat berjalan dengan kelengkapan data atau dokumen pada setiap tahapannya. Diperlukan pengelolaan KP yang dapat mengatur kegiatan KP dengan merekam semua data yang dibutuhkan pada setiap tahapan. Pengelola dan pengguna mendapatkan kemudahan dalam melaksanakan tugasnya dalam kegiatan KP dan menciptakan tertib pelaksanaan kegiatan KP yang didukung dengan data yang lengkap.

Rumusan permasalahan dalam penelitian ini adalah bagaimana desain aplikasi pengelolaan KP sesuai dengan kebutuhan pengelola dan pengguna. Pengembangan aplikasi KP didesain berbasis web menghasilkan prototype aplikasi pada sisi pengguna dan pengelola mulai dari pendaftaran KP sampai dengan seminar hasil KP. Tujuan dari penelitian yang dilakukan adalah menganalisis kebutuhan pengembangan aplikasi KP dan membuat desain aplikasi pengelolaan KP sesuai kebutuhan pengelola dan pengguna.

\section{TINJAUAN PUSTAKA}

\section{Analisis dan Desain Sistem}

Analisis dan desain sistem (ADS) adalah istilah yang luas untuk mendeskripsikan metodologi untuk mengembangkan Sistem Informasi berkualitas tinggi yang menggabungkan teknologi informasi (TI), orang dan data untuk mendukung kebutuhan bisnis. Teknik ADS tidak hanya terbatas pada sistem TI dan dapat digunakan untuk menciptakan apa saja, dari rumah keluarga hingga stasiun luar angkasa internasional (Ramakrishnan, 2012).

Kunci sukses dalam bisnis adalah kemampuan untuk mengumpulkan, mengatur, dan menafsirkan informasi. ADS merupakan metodologi yang terbukti memberi manfaat membantu usaha besar dan kecil. Tujuan utama dari analisis dan desain sistem adalah untuk memperbaiki sistem organisasi melalui penerapan perangkat lunak yang dapat membantu karyawan menyelesaikan tugas bisnis utama dengan lebih mudah dan efisien (Valacich, 2015). Aplikasi juga disebut sistem, dirancang untuk mendukung fungsi atau proses organisasi tertentu, seperti manajemen persediaan, penggajian, atau analisis pasar. Tujuan dari penggunaan aplikasi adalah untuk mengubah data menjadi informasi. 
Metodologi, teknik, dan alat terbukti penting dalam proses rekayasa perangkat lunak. Metodologi adalah urutan pendekatan langkah-demi-langkah yang membantu mengembangkan produk akhir. Sebagian besar metodologi menggabungkan beberapa teknik pengembangan, seperti pengamatan langsung dan wawancara dengan pengguna sistem saat ini.

Teknik adalah proses untuk memastikan bahwa pekerjaan dipikirkan dengan baik, lengkap, dan dapat dipahami oleh orang lain di tim proyek. Teknik memberikan dukungan untuk berbagai tugas, merencanakan dan mengelola aktivitas dalam proyek pengembangan sistem, membuat diagram bagaimana sistem akan berfungsi, dan merancang laporan bagi penggunanya. Alat adalah program komputer, seperti computer-aided software engineering (CASE), yang mempermudah penggunaan teknik tertentu. Ketiga unsur ini metodologi, teknik, dan alat bekerja sama membentuk pendekatan organisasi terhadap analisis dan desain sistem.

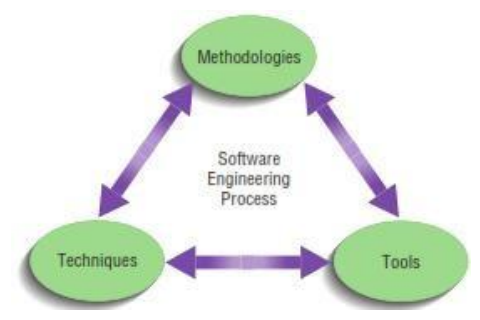

Gambar 1 Proses rekayasa perangkat lunak

Saat ini, pengembangan sistem berfokus pada integrasi sistem. Integrasi sistem memungkinkan perangkat keras dan perangkat lunak dari vendor yang berbeda untuk bekerja sama dalam sebuah aplikasi. Ini juga memungkinkan sistem yang ada dikembangkan dalam bahasa prosedural untuk bekerja dengan sistem baru yang dibangun dengan lingkungan pemrograman visual.

Pemodelan bisnis adalah suatu kegiatan yang mendukung penemuan persyaratan sistem dengan membantu tim memahami konteks bisnis yang lebih luas dimana sistem nantinya akan beroperasi (Wazlawick, 2014). Pemodelan bisnis mempelajari dan memahami organisasi dan prosesnya, karena biasanya sistem yang akan dikembangkan tidak akan menjadi produk yang terisolasi, melainkan bagian organik dari konteks organisasi.

UML adalah sebuah "bahasa" yang telah menjadi standar dalam industri untuk menentukan, visualisasi, merancang dan mendokumentasikan artifact dari sistem software, untuk memodelkan bisnis dan sistem non-software lainnya. UML menjadi bahasa standar dalam pengembangan perangkat lunak yang memungkinkan para engineer untuk bertukar desain secara bebas (Watson, 2008).

\section{Kerja Praktek}

Ruang lingkup pekerjaan yang dilaksanakan pada saat KP harus memiliki relevansi dengan kompetensi yang diharapkan dari setiap program studi dimana hal ini dapat berupa usulan dari mahasiswa atau berasal dari tempat KP dilaksanakan. Terdapat 2 jenis aktivitas yang dilakukan yaitu:

1. Mahasiswa melakukan aktivitas 'bekerja' purna waktu (masuk setiap hari kerja) di tempat KP dan terlibat dalam kegiatan keseharian perusahaan/institusi dengan mengerjakan/diberikan tugas tertentu yang umumnya dapat diselesaikan selama pelaksanaan KP.

2. Mahasiswa berstatus pegawai/karyawan di perusahaan/instansi melakukan aktivitas 'projek' menyelesaikan KP dengan mengatur aktivitasnya untuk keperluan-keperluan data-data tertentu sesuai dengan aturan dan kebijakan dari perusahaan/institusi tempat KP.

Kerja Praktek yang dilakukan oleh mahasiswa bertujuan membangun mahasiswa yang siap dalam menghadapi permasalahan dan tantangan dunia usaha/kerja serta memiliki kemampuan dalam menganalisis permasalahan dalam lingkup teknologi, mendapatkan pengetahuan dan pengalaman sesuai dengan disiplin ilmu di lingkungan kerja sebenarnya sehingga mampu memberikan umpan balik berupa perkembangan keilmuan didalamnya, dan mendapatkan data-data yang dapat diangkat menjadi masalah untuk disusun dalam proposal tugas akhir mahasiswa.

\section{METODE PENELITIAN}

Kerja praktek yang dilakukan pada perguruan tinggi melibatkan aktor pimpinan, koordinator $\mathrm{KP}$, staf administrasi dan mahasiswa. Tahapan KP terdiri atas: sosialisasi, pendaftaran, pengusulan 
tempat KP, pengusulan proposal, pelaksanaan KP, pelaporan KP dan seminar KP.

Tahapan penelitian yang dilakukan adalah sebagai berikut:

1. Perencanaan dan Seleksi: tahap ini memiliki dua aktivitas utama:

a. Mengidentifikasi kebutuhan akan sistem KP baru.

b. Menyelidiki sistem dan menentukan lingkup sistem KP yang diusulkan

2. Analisis: analis secara menyeluruh mempelajari prosedur organisasi saat ini dan sistem informasi yang digunakan untuk melakukan tugas. Analisis memiliki beberapa subfase.

a. Melibatkan penentuan persyaratan sistem. Dalam subfasa ini bekerja dengan pengguna untuk menentukan apa yang diinginkan pengguna dari sistem yang diusulkan.

b. Mempelajari persyaratan dan menyusunnya sesuai dengan keterkaitannya, menghilangkan redundansi apapun.

c. Kemudian membandingkan alternatif ini untuk menentukan mana yang paling sesuai dengan persyaratan di dalam biaya, tenaga kerja, dan tingkat teknis yang bersedia dilakukan organisasi terhadap proses pembangunan.

Output dari tahap analisis adalah deskripsi dari solusi alternatif yang direkomendasikan. Setelah rekomendasi diterima oleh organisasi, selanjutnya membuat rencana untuk memperoleh perangkat keras dan perangkat lunak sistem yang diperlukan untuk membangun atau mengoperasikan sistem sesuai usulan.

3. Desain: mengubah deskripsi solusi alternatif yang disarankan menjadi spesifikasi sistem logis dan fisik. Tahap ini merancang semua aspek sistem dari layar input dan output ke laporan, database, dan proses komputer.

a. Desain logis tidak terkait dengan platform perangkat keras dan sistem perangkat lunak tertentu. Desain logis berkonsentrasi pada aspek bisnis dari sistem - yaitu, bagaimana sistem akan mempengaruhi unit fungsional dalam organisasi.

b. Desain fisik, mengubah desain logis menjadi spesifikasi fisik atau teknis. Desain fisik merancang berbagai bagian sistem untuk melakukan operasi fisik yang diperlukan untuk memudahkan pengambilan data, pengolahan, dan keluaran informasi. Desain fisik menentukan bahasa pemrograman, sistem database, struktur file, platform perangkat keras, sistem operasi, dan lingkungan jaringan yang akan dijalankan.

Produk akhir dari tahap desain adalah spesifikasi sistem fisik, yang disajikan dalam bentuk, seperti diagram atau laporan tertulis siap untuk dikonstruksi.

4. Implementasi dan Operasi: mengubah spesifikasi sistem menjadi sistem kerja yang diuji dan kemudian mulai digunakan. Implementasi meliputi coding, testing, dan installation. Coding menulis program yang membentuk sistem. Testing menguji program individual dan keseluruhan sistem untuk menemukan dan memperbaiki kesalahan. Installation sistem baru menjadi bagian dari aktivitas sehari-hari organisasi.

Selama operasi dilakukan perubahan yang diminta pengguna dan memodifikasi sistem agar mencerminkan perubahan kondisi bisnis. Perubahan ini diperlukan agar sistem tetap berjalan dan berguna.

\section{HASIL DAN PEMBAHASAN}

Aktivitas yang dilakukan dalam tahap ini meliputi identifikasi kebutuhan akan sistem dan menentukan lingkup sistem KP yang diusulkan. Pelaksanaan KP mahasiswa program studi dilingkungan FTIK adalah sesuai prosedur berikut: 


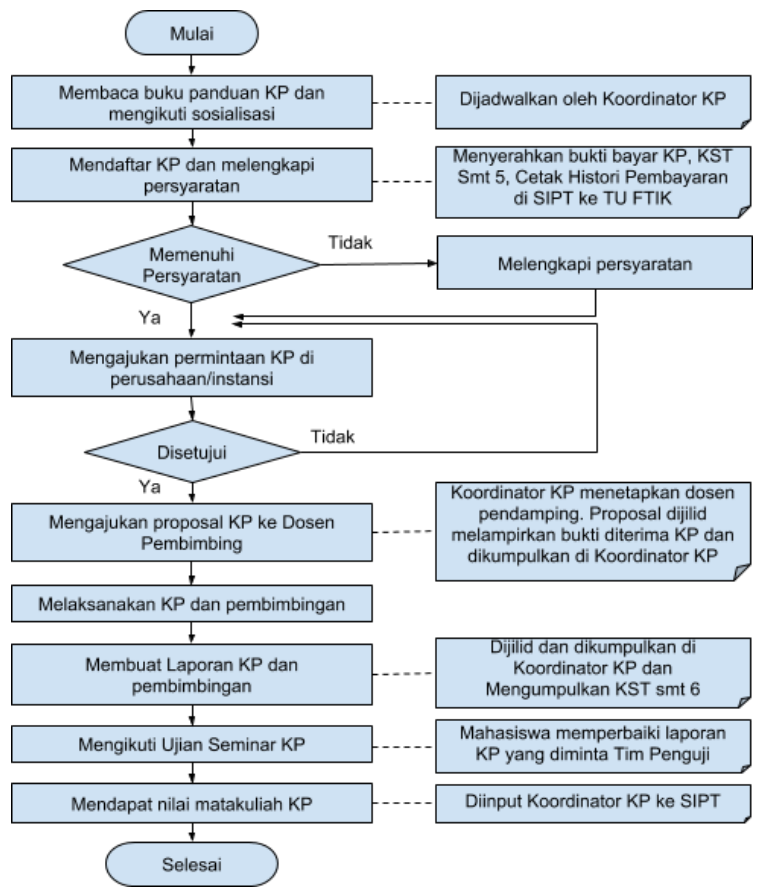

Gambar 2 Prosedur Kerja Praktek

Pengguna yang terlibat langsung dalam aplikasi ini adalah Dekan, Ketua Program Studi, Koordinator KP, Dosen dan Mahasiswa yang melaksanakan KP. Kebutuhan pengguna atas aplikasi adalah seperti tabel berikut:

Tabel 1: Kebutuhan Pengguna

\begin{tabular}{|c|c|c|}
\hline $\begin{array}{l}\text { Penggun } \\
\text { a }\end{array}$ & Kebutuhan & Keterangan \\
\hline \multirow[t]{5}{*}{ Mahasiswa } & Input Pendaftaran & Melakukan pengisian data pendaftaran KP \\
\hline & Input Proposal KP & Melakukan pengisian data usulan proposal KP \\
\hline & Input Kehadiran & Melakukan pengisian kehadiran KP \\
\hline & Input Laporan & Melakukan upload laporan KP \\
\hline & View Hasil Ujian & Melihat nilai dan koreksi untuk perbaikan laporan KP \\
\hline \multirow[t]{4}{*}{$\begin{array}{l}\text { Koordinator } \\
\text { KP }\end{array}$} & $\begin{array}{l}\text { Input Dosen } \\
\text { Pendamping }\end{array}$ & $\begin{array}{l}\text { Melakukan pengisian dosen pendamping dan mengatur } \\
\text { bimbingannya }\end{array}$ \\
\hline & Monitoring kehadiran & Melihat kehadiran mahasiswa dalam pelaksanaan KP \\
\hline & Input Seminar & Melakukan pengelolaan jadwal ujian seminar KP \\
\hline & $\begin{array}{l}\text { Input Nilai dan } \\
\text { Koreksi }\end{array}$ & Input hasil nilai seminar KP dan koreksi perbaikan \\
\hline \multirow{2}{*}{$\begin{array}{l}\text { Dosen } \\
\text { Pendamping }\end{array}$} & View Mahasiswa & Melihat mahasiswa bimbingan \\
\hline & View Jadwal & Melihat jadwal seminar \\
\hline \multirow{3}{*}{$\begin{array}{l}\text { Dekan dan } \\
\text { Ketua } \\
\text { program studi }\end{array}$} & View Mahasiswa & Melihat mahasiswa peserta KP \\
\hline & $\begin{array}{l}\text { View Dosen } \\
\text { Pendamping }\end{array}$ & Melihat dosen penamping KP \\
\hline & View hasil seminar & Melihat hasil seminar KP \\
\hline
\end{tabular}

Desain aplikasi yang dibangun dimodelkan dengan menggunakan usecase diagram. Mahasiswa dan Koordinator KP aktif melakukan input data yang dibutuhkan sistem sedangkan pimpinan dan dosen pendamping melihat data yang ada. 
Gambar 3 Usecase Diagram Kerja Praktek

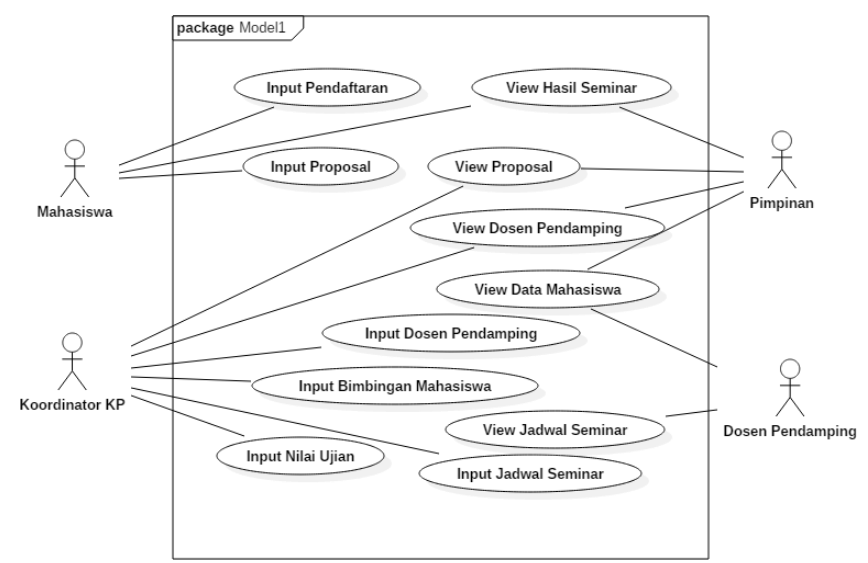

Aplikasi yang dibangun diimplementasikan berbasis web untuk kemudahan akses pengguna dengan multi platform. Program dibuat dengan memperhatikan rancangan UML pendekatan objek, perangkat lunak dibuat dalam klas-klas dengan fungsi masing-masing.

Cara menjalankan aplikasi melalui URL http:/kpftik.ubpkarawang.ac.id dengan browser. Dengan melakukan pengisian user login secara benar maka akan dapat menggunakan aplikasi sesuai akses pengguna masing-masing. Berikut adalah tampilan- tampilan layar aplikasi pengelolaan KP sebagai berikut:

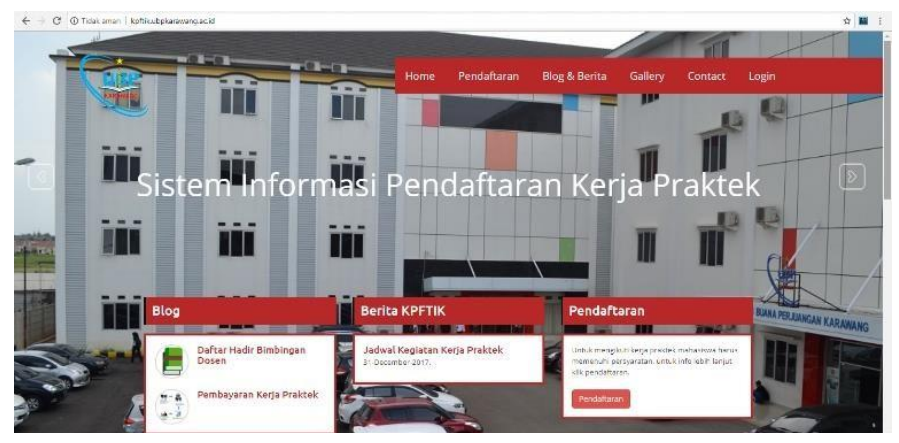

Gambar 4 Halaman muka aplikasi KP

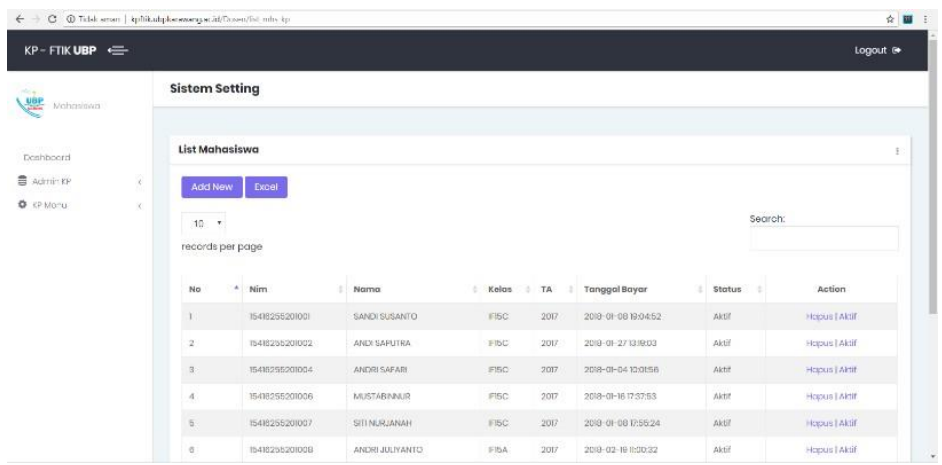

Gambar 5 Halaman mahasiswa peserta KP 


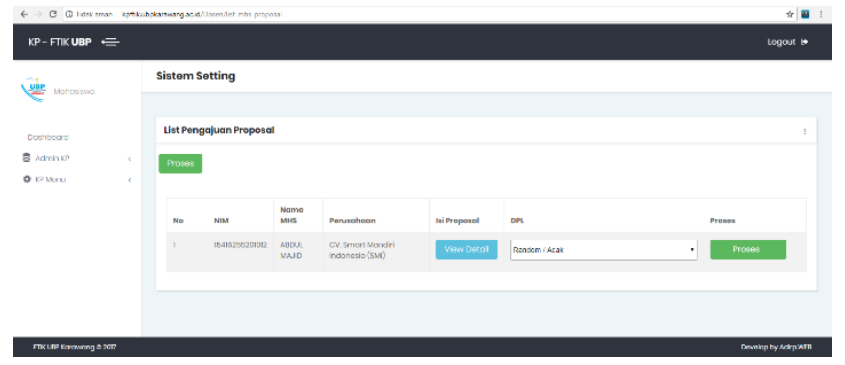

Gambar 6 Halaman pengajuan proposal

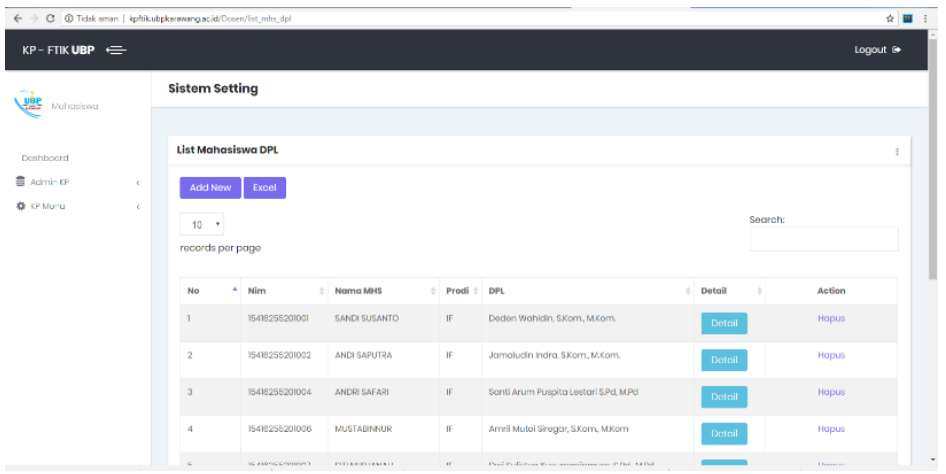

Gambar 7 Halaman dosen pendamping

Spesifikasi perangkat lunak yang dibutuhkan dalam perancangan dan implementasi adalah:

1. WampServer sebagai paket server local pada komputer pribadi berisi Apache2 server, bahasa pemrograman PHP and sistem manajemen database MySQL.

2. StarUML digunakan untuk menggambarkan model rancangan UML dari usulan perangkat lunak yang dikembangkan.

3. Sistem operasi dan paket pengolah kata yang sesuai.

Pengujian atas aplikasi KP dilakukan berdasarkan bagaimana aplikasi KP menghasilkan output yang diinginkan dari input yang disediakan. Pengujian ini dilakukan berdasarkan kode program (whitebox testing). Pengujian juga dilakukan dengan mengamati hasil eksekusi melalui data uji dan memeriksa fungsional dari perangkat lunak (blackbox testing). Pengguna melakukan input data dari tampilan aplikasi dan memeriksa kesesuaian hasil tampilan pada layar. Pengguna menguji dengan memilih input yang valid dan tidak valid dan kemudian menentukan output yang benar.

\section{KESIMPULAN}

Kesimpulan dari hasil penelitian ini adalah identifikasi kebutuhan pengelolaan KP terdiri atas kebutuhan pengguna, kebutuhan perangkat lunak dan perangkat keras. Hasil identifikasi untuk terwujudnya harapan pengguna maka diperlukan aplikasi berbasis web. Perancangan aplikasi sesuai dengan analisis sistem dirancang dalam aplikasi berbasis web untuk melayani pendaftaran, monitoring dan pelaporan KP yang diuji dalam ujian seminar KP. Aplikasi diuji coba pengguna dan menghasilkan alur pelaksanaan aplikasi yang sesuai kebutuhan dan aturan antarmuka pemakai.

Selanjutnya aplikasi dapat dikembangkan untuk seminar KP yang mencantumkan kehadiran peserta mahasiswa bukan peserta KP. Aplikasi dapat lebih baik diintegrasikan sistem informasi akademik untuk penyediaan data yang relevan. 


\section{DAFTAR PUSTAKA}

Joseph S. Valacich dkk, 2015, Essentials of Systems analysis and design, Pearson Education Limited, England Ramakrishnan S, 2012, System Analysis and Design, Journal Information Technology and Software Enggineering (JITSE) ISSN: 2165-7866 open access journal

Raul Sidnei Wazlawick, 2013, Object-oriented Analysis and Design for Information Systems Modeling with UML, OCL, dan IFML, Elsevier, USA

Tim Kerja Praktek, 2017, Panduan Kerja Praktek Fakultas Teknologi dan Ilmu Komputer, FTIK UBP Karawang 